\title{
A Linguagem, o Texto e o Documento no contexto da Ciência da Informação
}

\author{
Lenguaje, texto y documento en el contexto de la ciencia de la información
}

Language, text and document in the context of Information Science

\begin{abstract}
Heliomar CAVAti Sobrinho (1), João Batista Ernesto de Moraes (2), Mariângela Spotti Lopes FuJita (3)
(1) Universidade Federal do Ceará, Brasil $(2,3)$ Departamento de Ciência da Informação, Universidade Estadual Paulista, Marilia, Brasil (1) heliomarcavati@gmail.com (2) jota@marilia.unesp.br (3) fujita@marilia.unesp.br
\end{abstract}

\begin{abstract}
Resumen
Se discute la relación entre los conceptos de "texto","documento" e "información", con el objetivo de precisar el concepto de documento, especialmente en el ámbito de la organización y gestión de la información económica. El documento es un soporte en el que está registrada o manifestada una información. El documento, por tanto, es material, posee una intención, puede ser organizado y tratado para su mejor diseminación, presenta una tematicidad y un contexto específicos.
\end{abstract}

Palabras clave: Ciencia de la información. Documento. Texto. Leguaje. Definición. Información financiera.

\section{Introdução}

A análise do conceito de texto de Koch e Travaglia (2006) e documento de Briet, citada por Bukland (1997), assim como as concepções complementares de Guimarães e Moraes (2007) relacionadas ao conteúdo temático de um documento, nos leva a pensar na possibilidade de que são conceitos imbricados, tanto no seu significado e significante - percebido pelo observador da área da Ciência da Informação no que diz respeito ao seu objeto de estudo principal que é a informação sígnica contida em um documento -, quanto no signo em si, no sentido de que representam a mesma coisa: uma informação/mensagem.

Assim, pode-se inferir que os conceitos de documento e de texto estão relacionados e que são "quase-sinônimos" por possuírem algumas características em comum, dentre outras, como a Evidência, a Materialidade e capacidade de serem processados e de serem percebidos enquanto fenômeno (Briet citada por Buckland, 1997); a Tematicidade e a Atinência (Guimarães; Moraes, 2007); e a Informatividade, a Intertextualidade, a Intencionalidade e a Aceitabilidade (Koch; Travaglia, 2006).

Esta análise será contextualizada na Ciência da Informação - ciência pós-moderna, inter e mul-

\begin{abstract}
The relation among the concepts text, document and information is discussed, with the aim of clarifying the concept of document, with a focus in the field of economic information organization and management. A document is a medium in which information is recorded and manifested. A document is, thus, material, has a purpose, can be organized and treated for its improved dissemination, and has a specific subject and context.
\end{abstract}

Keywords: Information Science. Document. Text. Lenguage. Definition. Financial information.

tidisciplinar -, ou seja, "dentro" de um novo paradigma científico que a caracteriza como uma nova ciência que recebe e fornece aporte conceitual e metodológico de outras ciências como a Linguística, a Comunicação, a Biblioteconomia e a Documentação, dentre outras, conforme veremos a seguir.

\section{A Interdisciplinaridade no contexto da Ciência da Informação}

Segundo Kuhn (1993), a construção de novos paradigmas, através dos exemplos verificados nas revoluções copernicana, newtoniana, química e einsteiniana, foi precedida de um estado anômalo, ou de "crise paradigmática", pois exigiu a destruição em larga escala de paradigmas e grandes alterações nos problemas e técnicas da ciência normal, ou seja, para amadurecer ou criar um paradigma novo é necessário que haja uma revolução científica que são "aqueles episódios de desenvolvimento não-cumulativo, nos quais um paradigma mais antigo é total ou parcialmente substituído por um novo, incompatível com o anterior" (Kuhn, 1993, p. 125).

É o que está ocorrendo, de certa forma, com a Ciência da Informação - e o seu principal objeto de estudo, a Informação - que vive a sua crise de paradigmas, ou seja, de conceituação e defi- 
nição de parâmetros, tendo que remodelar/agregar os paradigmas da Biblioteconomia, Documentação, Museologia e Arquivologia, assim como suas colunas coadjuvantes, que são: a Ciência da Comunicação, a Ciência da Computação (tecnologia), a Linguística, dentre outras como a Administração, a Economia e a Psicologia, cada vez mais intrínsecas entre si, percebendo-se a sua complexidade paradigmática aumentando, como demonstrado na revisão realizada por Robredo (2003), compreendendose ainda, nitidamente, a saudável "proliferação de versões de uma teoria, que é um sintoma muito usual de crise" (Kuhn, 1993, p. 110) pela qual passa, que está permitindo a elaboração de seu novo paradigma multi e interdisciplinar.

Ou seja, sob a ótica kuhniana, estaria a Ciência da Informação saindo de um processo científico revolucionário, encontrando-se - depois de passar por um estado anômalo em que era confundida com outras disciplinas como a Biblioteconomia, a Documentação e a Comunicação, por exemplo - em um estado pós-crise constituindo um novo estado paradigmático, caracterizada como uma ciência pós-moderna, haja vista que seus métodos científicos exigem critérios interdisciplinares e que seu(s) objeto(s) de estudo sejam multidisciplinares, e isto sem falar nas infinitas possibilidades contextuais em que podem ser aplicados seus métodos, leis e teorias.

Embora Kobashi e Tálamo (2004) vejam com ressalva os empréstimos conceituais de disciplinas como a Comunicação, por exemplo, pela Ciência da Informação, pois geram indeterminação terminológica e, consequentemente, problemas na caracterização do seu campo conceitual, tomado este cuidado, é exatamente na apropriação dos recursos e teorias interdisciplinares, que somados, a potencializam na difícil missão de organizar o fluxo de informação de bibliotecas, empresas, indústrias, escritórios e governos, utilizando-se até mesmo dos recursos das ciências biológicas, como a taxonomia que a auxilia na classificação das palavras.

Considerando, portanto estas características pós-modernas de multi e interdisciplinaridade torna-se necessário, então, considerá-la sob a ótica do pensamento pós-moderno, onde a ordem, a separabilidade e a lógica são complementadas pelas suas três vertentes: discutir sem dividir, a imprevisibilidade e a oposição da racionalização fechada à racionalização aberta, preconizadas por Morin (1998).

Sua natureza interdisciplinar, por exemplo, é analisada por Saracevic (1995), que, dentre outras abordagens, relaciona-a com quatro assuntos principais: Ciência da Computação, Bi- blioteconomia, Ciência Cognitiva e Comunicação, afirmando-a como uma ciência de resolução de problemas, sendo que Wersig (1993), além de afirmá-la como interdisciplinar, ressalta seu aspecto social.

Aspecto este importante por ser a Ciência da Informação orientada para responder a necessidade informacional da sociedade enquanto $\mathrm{Ci}$ ência Social Aplicada, ou seja (Le Coadic, 1996, p. 21):

A Ciência da Informação, com a preocupação de esclarecer um problema social concreto, o da informação, e voltada para o ser social que procura informação, coloca-se no campo das ciências sociais (das ciências do homem e da sociedade), que são o meio principal de acesso a uma compreensão do social e do cultural.

Não por acaso que o próprio Le Coadic (1996, p. 11) instituiu, analogamente ao esquema econômico clássico de produção-distribuiçãoconsumo, o modelo social do ciclo da informação (Figura 1).

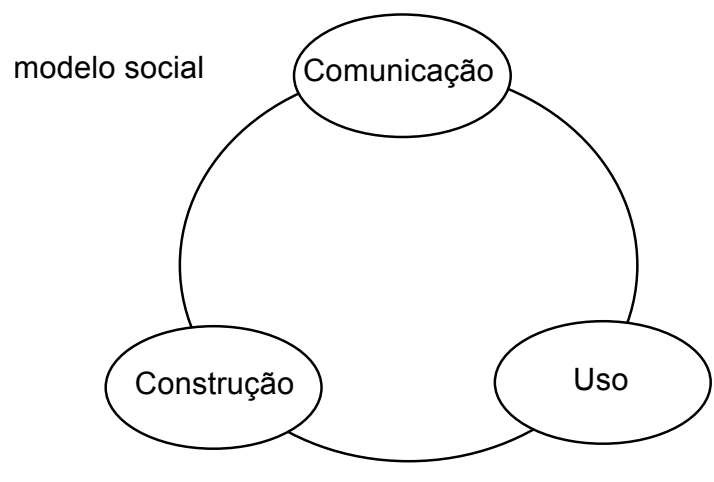

Figura 1. O Ciclo da Informação (Le Coadic, 1996, p. 11)

Portanto, neste trabalho, refletiremos sobre a perspectiva da Ciência da Informação como uma ciência social apoiada na tecnologia e que tem como objeto de estudo as "propriedades gerais da informação (natureza, gênese, efeitos)" e os seus processos e produtos de construção, comunicação e uso da informação. (Le Coadic, 1996, p. 26).

Assim, fica evidente que o estudo dos conceitos de Texto e Linguagem, enquanto conteúdo informacional de um Documento, suporte da informação registrada, faz-se necessário, pois não se constrói um sistema de informação sem a intenção de torná-lo comunicável e disponível para uso. 


\section{A Linguagem como elemento de representação do conteúdo do documento}

A informação, objeto de estudo da Ciência da Informação, segundo Barreto (1999), tem como função agregar conhecimento à sociedade através da modificação do estado de consciência dos indivíduos que a constituem, o que permite o seu aperfeiçoamento constante, ou seja, a sociedade que se priva de informação e que se fecha em si mesma está fadada à estagnação intelectual, moral, econômica e social, o que nos leva a deduzir que quanto mais a informação for disseminada mais os indivíduos poderão escoIher as que melhor the convêm no aprimoramento de suas vidas quanto à execução dos seus papéis sociais, seja como cidadãos nos locais públicos e coletivos, seja como profissionais no trabalho gerando inovações tecnológicas ou simplesmente como seres mais humanizados nas relações familiares.

Portanto, informação pode ser considerada, segundo Barreto (1999, p. 167) como:

Conjuntos significantes com a competência e a intenção de gerar conhecimento no indivíduo, em seu grupo, ou a sociedade [...] instrumento modificador da consciência do homem e de seu grupo social.

Buckland (1991) caracteriza a "informaçãocomo-coisa" de especial interesse no estudo dos sistemas de informação. É com a informação neste sentido que os sistemas de informação lidam diretamente. Bibliotecas lidam com livros; sistemas de informação, à base de computador, manuseiam dados na forma de bits e bytes físicos; os museus lidam diretamente com objetos, ou seja, somente informações registradas podem basear sistemas de informação.

Para Le Coadic (1996, p. 5),

Informação é um conhecimento [nota de roda-pé: Um conhecimento é o resultado do ato de conhecer, ato pelo qual o espírito apreende um objeto. Conhecer é ser capaz de formar a ideia de alguma coisa; é ter presente no espírito. Isso pode ir da simples identificação (conhecimento comum) à compreensão exata e completa dos objetos (conhecimento científico). O saber designa um conjunto articulado e organizado de conhecimentos a partir do qual uma ciência - um sistema de relações formais e experimentais - poderá originar-se] inscrito (gravado) sob a forma escrita (impressa ou numérica), oral ou audiovisual... o objetivo da informação permanece sendo a apreensão de sentidos ou seres em sua significação, ou seja, continua sendo o conhecimento; e o meio é a transmissão do suporte, da estrutura.
Neste sentido, para o profissional da informação, faz-se necessário estruturar o seu conhecimento baseado em representações sígnicas, cuja tematicidade documental possa ser compreendida e tratada cientificamente.

Conhecimento este que, segundo Tálamo (2004), requer três elementos em sintonia: o sujeito, a linguagem e o objeto.

O conhecimento, ou mais exatamente sua produção, requer três elementos para se concretizar: o sujeito, a linguagem e o objeto a ser conhecido. Embora banal esta afirmação, sua implicação para a compreensão do modo pelo qual o processamento intelectual da informação se desenvolve é fundamental. De fato, não se pode conceber um processo de conhecimento na ausência do sujeito. Quem conhece, por sua vez, conhece sempre algo. E para isso é fundamental a ação da linguagem, isto é do sistema simbólico. É, portanto, na relação entre esses três componentes que interações entre processos, estratégias e representações se estabelecem dando origem à base cognitiva das capacidades humanas que respondem pela construção do conhecimento. (Tálamo, 2004, p. 2-3).

Não é por acaso que McGarry (1999, p. 17) enfatiza que "a linguagem é o veículo fundamental da comunicação humana", portanto, é o veículo fundamental para a realização do fluxo da informação em todas as suas fases.

A Linguagem está presente em todos os processos do modelo social do Ciclo da Informação: construção, comunicação e uso, "que se sucedem e se alimentam reciprocamente" (Le Coadic, 1996, p. 10-11), principalmente na Comunicação que, se não for compreensível para quem a transmite e a recebe, não só no domínio dos símbolos e significados da linguagem, mas na compreensão cultural um do outro, através de uma intermediação do repertório de cada um, acaba não favorecendo o diálogo e a geração de conhecimento.

Dialogicidade esta percebida por Tálamo (1997, p. 10) na "socialização" e "na promoção de fluxos de várias ordens visando à interlocução [diálogo, portanto] adequada", referindo-se à linguagem documentária.

Para Freire (1975, p. 70),

[...] a comunicação é essencialmente lingüística [...] a comunicação eficiente exige que os sujeitos interlocutores incidam sua "ad-miração" sobre o mesmo objeto; que o expressam através de signos lingüísticos pertencentes ao universo comum a ambos, para que assim compreendam de maneira semelhante o objeto da comunicação. Nesta comunicação [Dialógica], que se faz por meio de palavras, não pode ser rompida a relação pensamento-linguagem-contexto ou realidade. 


\section{E ainda (ibidem, p. 71),}

A compreensão significante dos signos, por sua vez, exige que os sujeitos da comunicação sejam capazes de reconstituir em si mesmos [através de seus repertórios], de certo modo, o processo dinâmico em que se constitui a convicção expressa por ambos através dos signos lingüísticos.

A comunicação dialógica ocorre, portanto, de acordo com o universo comum a ambos, ou seja, seu repertório interno, através da comunicação permeada pela linguagem contextualizada sobre um objeto cognoscível, que se consubstancia em um novo repertório ou pensamento dos sujeitos.

Ao observar, por exemplo, a partitura (Figura 1) da música clássica "Cânon em Ré Maior" (1680), de Pachebel (1987), dependendo do conhecimento e informação que o sujeito tiver, a priori, este poderá interpretá-la como um desenho torto e sem sentido.

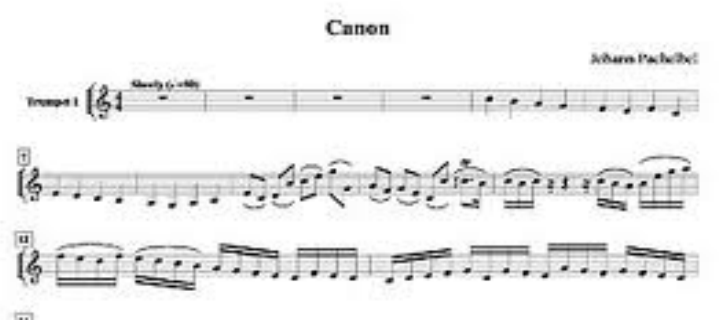

Figura 1: Parte da partitura "Cânon em Ré Maior".

Um sujeito com conhecimento e informação mais generalizados saberá que é um instrumento de execução de uma determinada música.

Um músico de formação geral compreenderá que, com um instrumento adequado, poderá executá-la e "senti-la".

No entanto, um sujeito, músico, especialista em música clássica e que já tenha ouvido e "sentido" a música referida, ao visualizar a partitura "ouvirá" em sua mente a música, por meio da relação perfeita entre o signo (a partitura), o significado (a música) e a imagem acústica, o significante (a música executada em sua mente).

Música esta que, ao ser executada por violinistas, não é um documento, a não ser que seja ou esteja materializada em algum suporte.

Tais considerações nos levam a questionar como organizar e tratar este tipo de documento? Quais os critérios de indexação deverão nortear a sua política de indexação? Seria possível e fidedigno utilizar, como indexadores, os sentimentos que a música desperta, utilizando-se de estudos da musicoterapia, tornando-se, assim, mais um recurso de auxílio aos profissionais que lidam com este tipo de documento: psicólogos, terapeutas, músicos e amantes da música clássica?

Portanto, a Linguagem consubstancia-se em informação quando há uma intencionalidade entre dois sujeitos, com repertórios simbólicos afins, possibilitando o seu registro em um documento, e, consequentemente, a sua organização e tratamento.

\section{Elementos e características do conteúdo do documento: signo, texto, tematicidade}

Ora, compreendendo que a linguagem é o veículo da comunicação humana e que a mesma está em todo o processo do ciclo da informação, que é linguístico, ou seja, textual, independente do formato, forma ou contexto, faz-se necessário refletir sobre a sua estrutura mínima que é o signo linguístico, que agregados constituem o conteúdo de um documento, cuja relevância temática é o que mais importa ao organizá-lo e tratá-lo para viabilizar a sua disseminação.

Comecemos pela conceituação de signo como a combinação de conceito e da imagem acústica proposta por Saussure (2006): signo é a totalidade da soma de suas duas partes: o significado e o significante.

Com a intenção de resolver uma questão de terminologia, Saussure (2006) propõe substituir conceito por significado e imagem acústica por significante, mantendo o termo signo designando a união do significado e do significante.

No entanto, para melhor entendermos a questão da representatividade de um signo, convém refletir sobre o que Saussure (2006, p. 80) conceitua como signo linguístico e imagem acústica, que ele propõe substituir por significante e conceito por significado.

O signo linguístico une não uma palavra, mas um conceito e uma imagem acústica. Esta não é o som material, coisa puramente física, mas a impressão (empreinte) psíquica desse som, a representação que dele nos dá o testemunho de nossos sentidos; tal imagem é sensorial e, se chegamos a chamá-la "material", é somente neste sentido, e por oposição ao outro termo da associação, o conceito, geralmente mais abstrato. [nota de rodapé: ...a imagem acústica é por excelência a representação natural da palavra enquanto fato de língua virtual, fora de toda realização pela fala.]

Quanto à linguagem textual, que, independente de ser oral ou escrita, constitui-se de um texto, conceituado, segundo Koch e Travaglia (2006, p. 10), como uma: 
Unidade linguística concreta (perceptível pela visão ou audição), que é tomada pelos usuários da língua (falante, escritor/ouvinte, leitor), em uma situação de interação comunicativa, como uma unidade de sentido e como preenchendo uma função comunicativa reconhecível e reconhecida, independentemente de sua extensão.

Texto, portanto, é algo que está em evidência, ou seja, é percebido pelos sentidos humanos entre dois ou mais sujeitos, caracterizando a sua intenção de comunicabilidade dentro de um contexto de uma determinada realidade, com o objetivo de informar um conhecimento.

Parte-se do pressuposto de que os autores distinguem "interação comunicativa" - vontade de comunicar uma informação/algo - da "função comunicativa" - a comunicação em si, ou seja, o canal por onde passa uma mensagem, através dos seus respectivos signos.

Esta mensagem (conjunto de signos), carregada de um sentido (o significado e o seu significante) informacional, pode-se considerar como a informação conceituada por Barreto (1999, p. 167):

Conjuntos significantes com a competência e a intenção de gerar conhecimento no indivíduo, em seu grupo, ou a sociedade.

Assim, a informação ou o conteúdo informacional do documento possui dois níveis: "uma tematicidade propriamente dita e o significado (meanings)", sendo a tematicidade intrínseca ao documento e permanente e o seu significado mutável. (Beghtol, citada por Guimarães, Moraes, 2006, p. 2-3).

Assim, tem-se (...) a tematicidade como algo intrínseco ao documento, de natureza relativamente permanente, integrando a essência do mesmo, ao passo que o significado é mutável em função do local, do momento histórico, do interesse do usuário, etc.

A mutabilidade que segundo Saussure (2006, p. 86) ocorre no significado - que fatores diversos podem se modificar -, mas não no signo que em

um dado estado de língua é sempre o produto de fatores históricos e são esses fatores que explicam porque o signo é imutável, vale dizer, porque resiste a toda substituição.

Após abordar o conceito de signo, significante e o seu significado, dos quais o texto é constituído, com a sua tematicidade delimitada, podemos inferir que um documento é o suporte onde está "registrado" ou "manifestado" uma informa- ção sígnica, considerando para fins lógicos, neste artigo, documento sob o ponto de vista de Buckland (1991), que ao inferir às discussões de Briet (1951, citada por Buckland, 1997, p. $805)$ chega às seguintes considerações sobre as suas características:

- Há materialidade: objetos físicos e sinais físicos somente;

- Há intencionalidade: pretende-se que o objeto seja tratado como evidência;

- Os objetos tem que ser processados: eles têm de ser transformados em documentos;

- O objeto precisa ser percebido como um documento (fenomenologia).

Assim, a análise entre o conceito de texto de Koch e Travaglia (2006) e documento de Briet, citada por Buckland (1997), assim como as concepções complementares de Guimarães e Moraes (2007) relacionadas ao conteúdo temático de um documento nos levam a pensar na possibilidade de que são conceitos imbricados tanto no seu significado e significante - percebido pelo observador da área da Ciência da Informação no que diz respeito ao seu objeto de estudo principal que é a informação sígnica contida em um documento -, quanto no signo em si, no sentido de que representam a mesma coisa: uma informação/mensagem.

Assim, pode-se inferir que os conceitos de documento e de texto estão relacionados e que são "quase-sinônimos" por possuírem algumas características em comum, dentre outras, como as seguintes, melhor visualizadas no Quadro I:

- Evidência; Materialidade; e capacidade de serem processados e de serem percebidos enquanto fenômeno (Briet citada por Buckland, 1997);

- Tematicidade; Atinência (Guimarães, Moraes, 2007);

- Informatividade; Intertextualidade; Intencionalidade; Aceitabilidade (Koch, Travaglia, 2006).

Um documento, portanto, é material, possui uma intenção em evidência, sendo passível de ser organizado e tratado para ser disseminado, cujo conteúdo apresenta uma tematicidade específica e delimitada, expressa, textualmente, com coesão, coerência, que se consubstanciam em informação, aceita (reconhecida) em um dado contexto (situacionalidade). 


\begin{tabular}{|c|c|c|}
\hline Autores & Elementos & Conceito \\
\hline \multirow{3}{*}{$\begin{array}{l}\text { Briet citada por } \\
\text { Buckland, } 1997 .\end{array}$} & Evidência & Há intencionalidade: pretende-se que objeto seja tratado como evidência. \\
\hline & Materialidade & Refere-se a objetos físicos e sinais físicos somente. \\
\hline & $\begin{array}{l}\text { Processo } \\
\text { Fenomênico }\end{array}$ & $\begin{array}{l}\text { Os objetos tem que ser processados: eles tem de ser transformados em } \\
\text { documentos. O objeto precisa ser percebido como um documento } \\
\text { (fenomenologia). }\end{array}$ \\
\hline $\begin{array}{l}\text { Guimarães; } \\
\text { Moraes, } 2007 .\end{array}$ & $\begin{array}{l}\text { Tematicidade ou } \\
\text { Atinência }\end{array}$ & $\begin{array}{l}\text { Algo intrínseco ao documento, de natureza relativamente permanente, integrando } \\
\text { a essência do mesmo, ao passo que o significado é mutável em função do local, } \\
\text { do momento histórico, do interesse do usuário. }\end{array}$ \\
\hline \multirow{2}{*}{$\begin{array}{l}\text { Beaugrande e } \\
\text { Dressler citados por } \\
\text { Koch e Travaglia, } \\
2006 .\end{array}$} & Coesão & $\begin{array}{l}\text { Diz respeito ao modo, na estrutura superficial, de conexão entre as partes do } \\
\text { texto, em processo de transição natural, em processo de recuperação de } \\
\text { informação. }\end{array}$ \\
\hline & Coerência & $\begin{array}{l}\text { Diz respeito à estrutura profunda lógico-semântica que unifica os fatos do texto } \\
\text { em determinada direção argumentativa. }\end{array}$ \\
\hline \multirow{5}{*}{ Koch, 1997.} & Informatividade & O texto contém informações novas ao lado das antigas. \\
\hline & Intertextualidade & $\begin{array}{l}\text { Como reflexo da experiência do autor, o texto pode revelar, implícita ou } \\
\text { explicitamente, a sua relação com outro texto. }\end{array}$ \\
\hline & Intencionalidade & Todo texto tem um propósito definido pelo autor. \\
\hline & Aceitabilidade & $\begin{array}{l}\text { O texto se realiza efetivamente no processo de interação autor-leitor, e, portanto, } \\
\text { deve buscar a aceitabilidade do segundo. }\end{array}$ \\
\hline & Situacionalidade & O texto realiza a sua função efetiva dentro de adequada situação. \\
\hline
\end{tabular}

Quadro I: Relação das características de documento e texto

Logo, um documento, por exemplo, cujo conteúdo evidencie uma tematicidade econômica em um texto coeso e coerente, se consubstancia em um Indicador Econômico que ao informar aspectos da realidade econômica, representando um estado desta, possui atributos da informação, objeto de estudo da Ciência da Informação, constituindo-se em um tipo de Informação Econômica.

Esta Informação Econômica, relevante para o desenvolvimento de uma melhor qualidade de vida em todos os planos, desde a definição de políticas que satisfaçam às necessidades básicas do ser humano, passando pela proposição de investimentos industriais com fins de exportação em longo prazo, até a geração de inovações tecnológicas, ou seja, fomenta, se bem utilizada, o desenvolvimento econômico em sua plenitude, cumprindo a sua função sócioeconômica (Jannuzzi, Cavati Sobrinho, 2005).

A informação econômica, portanto, "não está registrada no éter", mas em um suporte textual materializado e passível de tratamento e organização, como nos Boletins de Conjuntura Econômica, sejam impressos ou eletrônicos.

Dependendo do suporte e do formato da informação econômica, ela deverá ser processada, em todo o contínuo lógico de seu fluxo, desde a produção até a sua utilização, com critérios diferenciados; a informação disponibilizada em um homebroker de uma operadora da Bolsa de Valores, que ocorre em tempo real, deverá ter um tratamento (se possível) diferenciado da disponibilizada em um Boletim de Conjuntura Econômica que, normalmente, é publicado meses depois do fato ocorrido, servindo como instrumento de análise de conjunturas futuras aumentando a capacidade de decisão correta, através da diminuição do grau de incerteza e risco.

\section{Considerações finais e algumas reflexões}

Conclui-se, dessa forma, que o documento, é material, possui uma intenção em evidência, sendo passível de ser organizado e tratado para ser disseminado; o seu conteúdo apresenta uma tematicidade específica e delimitada, expressada, textualmente, com coesão e coerência, que se consubstanciam em informação, aceita (reconhecida) em um dado contexto (situacionalidade) e, ainda, que o Texto é intrínseco a um Documento, independente do suporte deste, possuindo os seguintes elementos em comum: evidência; materialidade; capacidade de serem processados e de serem percebidos enquanto fenômeno; tematicidade; atinência; 
informatividade; intertextualidade; intencionalidade e aceitabilidade.

Cabe, portanto, à Ciência da Informação, utilizando-se da área de estudo de organização e representação da informação e da sua interdisciplinaridade, a função de criar instrumentos que potencializem a rentabilização do fluxo documental de qualquer ciclo informacional, tendo sob perspectiva os elementos acima citados.

Estas reflexões, dentre as várias possíveis, denotam a importância de definições de parâmetros na elaboração de uma política de indexação no tratamento de qualquer tipo de acervo, seja em que suporte for, eletrônico ou não, para se obter êxito na sua disseminação, através de um dos princípios da Biblioteconomia, no cumprimento das cinco leis de Ranganathan (1967), aprofundados e ressignificados por Rajagopalan e Rajan (1984), citados por Nice Figueiredo (1992, p. 189):

1. a informação é para o uso;

2. a cada usuário sua informação;

3. cada informação a seu usuário;

4. economize o tempo do usuário - e o seu corolário: economize o tempo dos cientistas da informação; e

5. um sistema de informação é um organismo em crescimento.

No entanto, antes, ou no contexto das definições destes parâmetros, deve-se estabelecer a delimitação do conteúdo do conjunto de documentos, a sua área temática e a conceituação do documento da área específica, ou seja, a sua organização e tratamento, visando a ter o máximo de clareza que permitirá o estabelecimento de um fluxo de informação transparente e o alcance do seu objetivo maior: recuperá-la e disponibilizá-la para uso com eficiência e eficácia.

\section{Referencias}

Barreto, Aldo de Alburqueque (1999). A oferta e a demanda da informação: condições técnicas, econômicas e políticas. // Ciência da Informação. 28:2 (1999) 167-177.

Begthol, C (1986). Bibliographic classification theory and text linguistics: aboutness analysis, intertextuality and the cognitive act of classifying documents. // Journal of Documentation. 42:2 (June the 1986) 84-113.

Briet, S. (1951). Qu'est-ce que la documentation. Paris: EDIT.

Buckland, Michael Keeblem (1991). Information as Thing. // Journal of the American Society for Information Science. $45: 5$ (1991) 351-360
Buckland, Michael Keeblem (1997). What is a Document? Journal of American Society for Information Science. 48:9 (1997) 804-809.

Figueiredo, Nice Menezes de (1992). A Modernidade das Cinco Leis de Ranganathan. // Ciência da Informação. 21:3 (dezembro de 1992) 186-191.

Freire, Paulo (1975). Extensão ou comunicação? 2. ed. Rio de Janeiro: Paz e Terra.

Guimarães, J. A. C.; Moraes, Moraes, J. B. E. (2008). Análise Documental de conteúdo de textos literários narrativos: em busca do diálogo entre a concepções de aboutness/meaning e de percurso temático/percurso figurativo. // Gaspar, N. R.; Romão, L. M. S. (Org.). Discurso e texto: multiplicidade de sentidos na Ciência da Informação. São Carlos: EDUFSCar, 2008. 35-45.

Jannuzzi, Paulo de Martino; Cavati Sobrinho, Heliomar (2005). Fontes de Dados e Indicadores Econômicos no Brasil. // Bahia análise e dados. 15:1 (Junho de 2005) 75-90.

Kobashi, Nair Yumiko; Tálamo, Maria de Fátima G. M. (2004). A função da terminologia na construção do objeto da Ciência da Informação. // DataGramaZero: Revista de Ciência da Informação. 5:2 (Abril de 2004). http//www.dgzero.org (2005/12/25).

Koch, Ingedore (1997). A coesão textual. 7. ed. São Paulo: Contexto.

Koch, Ingedore; Travaglia, L.C (2006). A coerência textual. São Paulo: Contexto.

Kuhn, T. S. (1993). A estrutura das revoluções científicas. São Paulo: Perspectiva.

Le Coadic, Yves-François (1996). A ciência da informação. Brasília: Briquet de Lemos.

Mcgarry, Kevin (1999). O Contexto dinâmico da informação: uma análise Introdutória. Brasília: Briquet de Lemos.

Morin, Edgar (1998). Complexidade e liberdade. //Thot: Associação Palas Athenas. 67 (1998) 12-19.

Pachebel, Johann (1987). Cânon em Ré Maior [gravação de som]. Regente Thomas Schippers; Execução da Orquestra Sinfônica de Berlim. Rio de Janeiro: Philips, 1987. $1 \mathrm{Cd}$ (faixa 1; 29 min e 53 s.). Compositores lluminados.

Rajagopalan. J. S., Rajan, T.N (1984). Use of information in science and research with emphasis on national development some Indian experiences. // International Forum on Information and Documentation. 9:3 (1984) 3-9.

Ranganathan, Shiyali Ramamrita (1967). The Five Laws of Library Science. Bombay: Asia Publishing House.

Robredo, Jaime (2003). Da ciência da informação revisitada aos sistemas humanos de informação. Brasília: Thesaurus.

Saracevic, Tefko (1995). Interdisciplinary nature of information science. // Ciência da Informação. 24:1 (Março 1995) 36-41.

Saussure, Ferdinand de (2006). Curso de lingüística geral. 27 ed. São Paulo: Cultrix.

Tálamo, Maria de Fátima G. M (1997). Linguagem Documentária. São Paulo: APB.

Enviado: 2012-04-15. Versión corregida: 2012-07-19. Aceptado: 2012-08-20. 
